(1)

CrossMark

\title{
A randomised trial of high-flow nasal cannula in infants with moderate bronchiolitis
}

\author{
Philippe Durand (1) ${ }^{1}$, Tamazoust Guiddir ${ }^{1}$, Christèle Kyheng ${ }^{1}$, Florence Blanc ${ }^{2}$, \\ Olivier Vignaud ${ }^{3}$, Ralph Epaud $\mathbb{1}^{4}$, Frédéric Dugelay ${ }^{4}$, Isabelle Breant ${ }^{5}$, \\ Isabelle Badier ${ }^{6}$, Vanessa Degas-Bussière ${ }^{7}$, Florence Phan ${ }^{8}$, \\ Valérie Soussan-Banini ${ }^{9}$, Agnès Lehnert ${ }^{10}$, Célestin Mbamba $^{11},{ }^{\prime}$ Catherine Barrey ${ }^{12}$, \\ Cédric Tahiri ${ }^{13}$, Marion Decobert ${ }^{14}$, Marie Saunier-Pernaudet ${ }^{15}$, Irina Craiu ${ }^{1}$, \\ Mélanie Taveira ${ }^{16}$ and Vincent Gajdos ${ }^{16,17}$ for the Bronchopti study group ${ }^{18}$
}

@ERSpublications

This randomised trial found no evidence of lower rate of escalating respiratory support among patients receiving high-flow oxygen therapy admitted for a first episode of moderate bronchiolitis to the paediatric emergency department https://bit.ly/2xsvqJG

Cite this article as: Durand $\mathrm{P}$, Guiddir T, Kyheng C, et al. A randomised trial of high-flow nasal cannula in infants with moderate bronchiolitis. Eur Respir J 2020; 56: 1901926 [https://doi.org/10.1183/ 13993003.01926-2019].

\section{ABSTRACT}

Background: The objective was to determine whether high-flow nasal cannula (HFNC), a promising respiratory support in infant bronchiolitis, could reduce the proportion of treatment failure requiring escalation of care.

Methods: In this randomised controlled trial, we assigned infants aged $<6$ months who had moderate bronchiolitis to receive either HFNC at $3 \mathrm{~L} \cdot \mathrm{kg}^{-1} \cdot \mathrm{min}^{-1}$ or standard oxygen therapy. Crossover was not allowed. The primary outcome was the proportion of patients in treatment failure requiring escalation of care (mostly noninvasive ventilation) within 7 days following randomisation. Secondary outcomes included rates of transfer to the paediatric intensive care unit (PICU), oxygen, number of artificial nutritional support-free days and adverse events.

Results: The analyses included 268 patients among the 2621 infants assessed for inclusion during two consecutive seasons in 17 French paediatric emergency departments. The percentage of infants in treatment failure was $14 \%$ (19 out of 133) in the study group, compared to $20 \%$ (27 out of 135) in the control group (OR 0.66, 95\% CI 0.35-1.26; p=0.21). HFNC did not reduce the risk of admission to PICU (21 (15\%) out of 133 in the study group versus 26 (19\%) out of 135 in the control group) (OR 0.78, 95\% CI 0.41-1.41; $\mathrm{p}=0.45$ ). The main reason for treatment failure was the worsening of modified Wood clinical asthma score (m-WCAS). Short-term assessment of respiratory status showed a significant difference for $\mathrm{m}$-WCAS and respiratory rate in favour of HFNC. Three pneumothoraces were reported in the study group.

Conclusions: In patients with moderate bronchiolitis, there was no evidence of lower rate of escalating respiratory support among those receiving HFNC therapy.

Published online 16 July, 2020; republished 29 July, 2020 with amendments to an author forename.

This article has an editorial commentary: https://doi.org/10.1183/13993003.01020-2020

This article has supplementary material available from erj.ersjournals.com

This study is registered on http://clinicaltrials.gov with identifier: NCT02856165. All the individual participant data collected during the trial will be made available after deidentification.

Received: 3 Oct 2019 | Accepted after revision: 23 March 2020

Copyright @ERS 2020 


\section{Introduction}

Acute viral bronchiolitis remains the leading cause of acute respiratory failure in infants in developed countries [1-3]. As stated by both the American Academy of Pediatrics and related UK guidelines, treatment is mainly supportive and includes monitoring, low-flow oxygen therapy, hydration or nutritional support $[4,5]$. This approach remains the cornerstone of standard care, and thus far, no specific medical therapy has proven beneficial [6]. Over the past decade, high-flow nasal cannula (HFNC) has emerged as a promising method to provide respiratory support in children with severe bronchiolitis either during interhospital transfer or in the paediatric intensive care unit (PICU) [7-11]. Oxygen delivery with HFNC allows for the administration of a heated and humidified blend of air and oxygen at various flow rates $\geqslant 2 \mathrm{~L} \cdot \mathrm{min}^{-1}$ that can be matched to the patient's inspiratory flow. Various physiological effects have been demonstrated including flow rate-dependent distending pressure, decreased airway resistance and work of breathing, as well as dead-space washout. Nevertheless, no current evidence suggests that early or pre-emptive support with HFNC in either paediatric emergency departments (PEDs) or general wards is superior to standard care (e.g. low-flow oxygen therapy) for reducing the risk of acute respiratory failure leading to escalating respiratory support, which is mainly provided by nasal continuous positive airway pressure (nCPAP) $[2,12,13]$. Thus far, only two prospective randomised controlled trials (RCTs) have compared HFNC with low-flow oxygen therapy in patients with less severe bronchiolitis admitted to general wards, but both failed to clearly demonstrate a reduction in the length of oxygen therapy or in the proportion of patients transferred to the PICU $[14,15]$. Other issues regarding high-flow therapy include the potential for rapid deterioration outside the PICU in intermediate-level care (PEDs and wards), as well as the method's cost-effectiveness or the potential costs associated with overuse. Recent UK guidelines suggest that an RCT comparing HFNC and standard supplemental oxygen would be beneficial to address these questions [4]. Therefore, we performed an RCT evaluating high- versus low-flow oxygen therapy, including standard care, in infants with moderate-severity bronchiolitis (defined as a modified Wood clinical asthma score (m-WCAS) $>2$ and requiring supplemental oxygen) admitted to PEDs and subsequently general ward units. We aimed to determine whether HFNC in this setting could reduce the rate of treatment failure requiring escalation of care.

\section{Methods}

\section{Trial design}

This multicentre open-label RCT was performed in the emergency departments and general paediatric wards of 17 hospitals (a paediatric hospital network) in the southern and eastern suburbs of Paris, including 13 nontertiary regional/metropolitan hospitals. Only one of these centres (Bicêtre hospital) had access to an on-site PICU, while three had an on-site intermediate level unit. Three of the recruiting centres had previous experience with HFNC before starting the study.

Group education sessions with attending physicians, nurses, and junior medical officers were conducted in each recruiting centre before the start of the study. This training involved a planned visit to the emergency department and with ward staff by the lead investigator (PD) and clinical research associates (Marylise Adechian, Domitille Molinari) to present specific examples of HFNC drawn from video recordings. Clinicians were specifically trained in eligibility criteria involving the $\mathrm{m}$-WCAS score and how to respond to treatment failure during the study (supplementary table E1).

The study protocol was approved by the Paris-Ile de France XI ethics committee (2016-A00568-43). Written authorisation was obtained from both parents of each patient after appropriate information was provided.

Infants with moderate bronchiolitis who were seen at participating PEDs were eligible for the study. The inclusion criteria were as follows: a first episode of hospitalisation for bronchiolitis (as defined by

Affiliations: ${ }^{1}$ Pediatric Emergency Dept, Bicêtre University Hospital, Assistance Publique-Hôpitaux de Paris, Kremlin-Bicêtre, France. 'Villeneuve-Saint Georges Intercommunal Hospital, Villeneuve-Saint Georges, France. ${ }^{3}$ Meaux Hospital, Meaux, France. ${ }^{4}$ Créteil Intercommunal Hospital, Créteil, France. ${ }^{5}$ Melun Hospital, Melun, France. ${ }^{6}$ Poissy Hospital, Poissy, France. ${ }^{7}$ Sud-Francilien Hospital, Corbeil-Essonnes, France. ${ }^{8}$ Chartres Hospital, Chartres, France. ${ }^{9}$ Ambroise Paré University Hospital, Assistance Publique-Hôpitaux de Paris, Boulogne-Billancourt, France. ${ }^{10}$ Montargis Hospital, Amilly, France. ${ }^{11}$ Gien Hospital, Gien, France.

${ }^{12}$ Bry sur Marne Hospital, Bry sur Marne, France. ${ }^{13}$ Dourdan Hospital, Dourdan, France. ${ }^{14}$ Orsay Hospital, Orsay, France. ${ }^{15}$ Fontainebleau Hospital, Fontainebleau, France. ${ }^{16}$ Antoine Béclère University Hospital, Assistance Publique-Hôpitaux de Paris, Clamart, France. ${ }^{17}$ Centre for Research in Epidemiology and Population Health, INSERM U1018, Villejuif, France. ${ }^{18} \mathrm{~A}$ list of members of the Bronchopti study group can be found in the acknowledgements section.

Correspondence: Philippe Durand, Paediatric Intensive Care Unit, Bicêtre Hospital, Paris-Saclay University, Assistance Publique Hôpitaux de Paris, 78 rue du Général Leclerc, 94275 Le Kremlin Bicêtre, France. E-mail: philippe.durand2Qaphp.fr 
American Academy of Pediatrics clinical recommendations) in infants aged 7 days to 6 months with one episode of pulse oximetry-measured oxygen saturation $\left(S_{\mathrm{pO}_{2}}\right)<95 \%$ while on room air at any time before randomisation and m-WCAS between 2 and 5 at inclusion $[7,14,16]$. The agreement of at least one parent or legal guardian to participate in biomedical research, as well as affiliation with the public healthcare system (beneficiary or entitled), was required. Infants were not eligible if they had any of the following: urgent need for mechanical ventilation support either by nCPAP or the endotracheal route, a severe form of bronchiolitis defined by $\mathrm{m}$-WCAS $>5$ and the requirement for noninvasive ventilation, uncorrected cyanotic heart disease, innate immune deficiency, craniofacial malformation, congenital stridor and tracheotomy.

Included patients were randomly assigned to the control or HFNC group using an electronic system-based randomisation method and stratified according to centre (using a 1:1 allocation sequence ratio by two to four random blocks) within $48 \mathrm{~h}$ after admission (https://cleanweb-production3.aphp.fr). They received either standard oxygen therapy (up to $2 \mathrm{~L} \cdot \mathrm{min}^{-1}$ to maintain $S_{\mathrm{pO}_{2}}$ at $\geqslant 94 \%$ ) (control group) or HFNC therapy delivered via an Airvo 2 turbine through an Optiflow junior infant size cannula (OPT316) (Fisher \& Paykel Healthcare, Auckland, New Zealand) (setting at $3 \mathrm{~L} \cdot \mathrm{kg}^{-1} \cdot \mathrm{min}^{-1}$, min 7 to $\max 20 \mathrm{~L} \cdot \mathrm{min}^{-1}$, inspiratory oxygen fraction $\left(F_{\mathrm{iO}_{2}}\right)$ adjusted to obtain a similar $S_{\mathrm{pO}_{2}}$ target) (HFNC group). Crossover was not allowed. All patients received similar standard care at the discretion of the attending physician, but physiotherapy, steroids and inhaled bronchodilator drugs were discouraged.

Treatment failure criteria indicating release from the study were defined as follows: at least one of $F_{\mathrm{iO}_{2}}$ requirement on HFNC $>40 \%$ (HFNC group) or nasal flow oxygen $>2 \mathrm{~L} \cdot \mathrm{min}^{-1}$ (control group) in order to maintain $S_{\mathrm{pO}_{2}} \geqslant 94 \%$, elevated $\mathrm{m}$-WCAS score (i.e. by $\geqslant 1$ point) at hour 6 compared to baseline and/or any scores $>5$, refractory apnoea episodes $\left(>3\right.$ events. $\left.h^{-1}\right)$ and/or increasing arterial carbon dioxide tension compared to baseline and/or $>60 \mathrm{mmHg}$ at hour 6 .

In the HFNC group, the use of a pacifier was recommended to reduce mouth leaks. Weaning procedures were protocolised by reducing the flow rate by $2 \mathrm{~L} \cdot \mathrm{min}^{-1}$ increments every $8 \mathrm{~h}$ starting at hour 12 and when $F_{\mathrm{iO}_{2}}$ could be reduced to $\leqslant 25 \%$.

The Airvo 2 turbine, tubing, heated humidifiers, and prong cannulas (i.e. consumable materials) were provided to the participating centres during the study period by Fisher \& Paykel Healthcare, which had no other involvement in the study.

\section{Outcomes}

The primary end-point was the proportion of patients in each group that experienced treatment failure requiring escalating treatment within 7 days following randomisation. Escalating treatment was defined as the application of noninvasive or invasive ventilation in the overall population or the use of HFNC in the control group.

Secondary outcomes included the rates of transfer to the PICU among patients in treatment failure (either on-site or an intensive care unit referral centre), an assessment of short-term respiratory status (at hours 1, 6 and 12), paediatric general ward unit length-of-stay, oxygen support-free days and artificial nutritional support-free days.

\section{Statistical analysis}

The trial was designed to evaluate the superiority of HFNC in comparison to the standard of care in terms of failure rate. For the intention-to-treat analysis, the following assumptions were made: a 30\% event rate in the control group and a $15 \%$ event rate in the HFNC group, providing a relative risk reduction with HFNC of $\geqslant 50 \%$. This assumption was based on a literature analysis [10,17-19]. Assuming a $15 \%$ rate of patients enrolling despite not being eligible for randomisation, as well as consent withdrawals or loss to follow-up for the primary end-point, we estimated that 140 patients per group would give the study $\geqslant 80 \%$ power to demonstrate the superiority of HFNC (risk $\alpha=5 \%$ and $\beta=20 \%$ ). We did not plan an interim analysis.

Our primary analysis was conducted using an intention-to-treat approach, and it therefore included all randomised infants. Baseline characteristics of the patients in each group were reported using frequency distributions and descriptive statistics, including measures of central tendency and dispersion. Between-group differences were analysed using a t-test or Wilcoxon rank-sum test for continuous variables or a Chi-squared test for categorical variables, as appropriate, and are reported as estimated median differences (Hodges-Lehman estimate) or odds ratios with $95 \%$ confidence intervals. Kaplan-Meier curves were plotted to assess the time from enrolment to failure (i.e. requiring escalation of treatment) and were compared using a log-rank test. All analyses were conducted using Stata version 14 software (StataCorp, 
College Station, TX, USA) in accordance with the International Conference on Harmonisation Good Clinical Practice guidelines. $\mathrm{p}<0.05$ was considered statistically significant.

\section{Results}

\section{Patient characteristics}

From November 1, 2016 through March 31, 2017 and from October 1 to November 15, 2017, a total of 2621 patients admitted for bronchiolitis to the 17 PEDs of the participating centres were screened, of whom 271 underwent randomisation. Data on the primary outcome were available for 268 of these patients for the intention-to-treat analysis (figure 1). Demographics and clinical characteristics were similar at inclusion except for a slightly lower mean m-WCAS score value in the control group $(\mathrm{p}=0.028)$ (table 1$)$. Given that several patients were excluded after randomisation (figure 1), inclusions were prematurely ended at the discretion of the steering committee once the prespecified sample size was reached.

\section{Primary outcome}

HFNC did not improve the primary outcome among the 268 patients included in the intention-to-treat analysis. Failure occurred in 19 (14\%) out of 133 patients in the HFNC group and 27 (20\%) out of 135 patients in the standard oxygen therapy group (including nine patients treated with high-flow nasal cannula in an intensive care unit (ICU)) at 7 days after randomisation (table 2, figure 2). No patient underwent invasive ventilation during the study. The main reason for treatment failure was worsening $\mathrm{m}$-WCAS score in the first $6 \mathrm{~h}$ following randomisation. This complication accounted for 12 and 20 failures in the HFNC and control groups, respectively, and did not differ significantly between the two groups (supplementary table E2). Severity at the time of failure was evidenced by mean m-WCAS score and transcutaneous carbon dioxide tension $\left(P_{\mathrm{tCO}_{2}}\right)$ values. However, except for mean $P_{\mathrm{tCO}}$ value, which was significantly higher in the control group compared to the HFNC group, we did not find any between-group differences for oxygen requirement or apnoea events (supplementary table E2).

\section{Secondary outcomes}

Similarly, HFNC did not reduce the risk of admission to the ICU (neither on-site nor referral tertiary PICUs) (21 (15\%) in the HFNC group versus $26(19 \%)$ in the control group ( $\mathrm{p}=0.45))$ (table 2). The mean

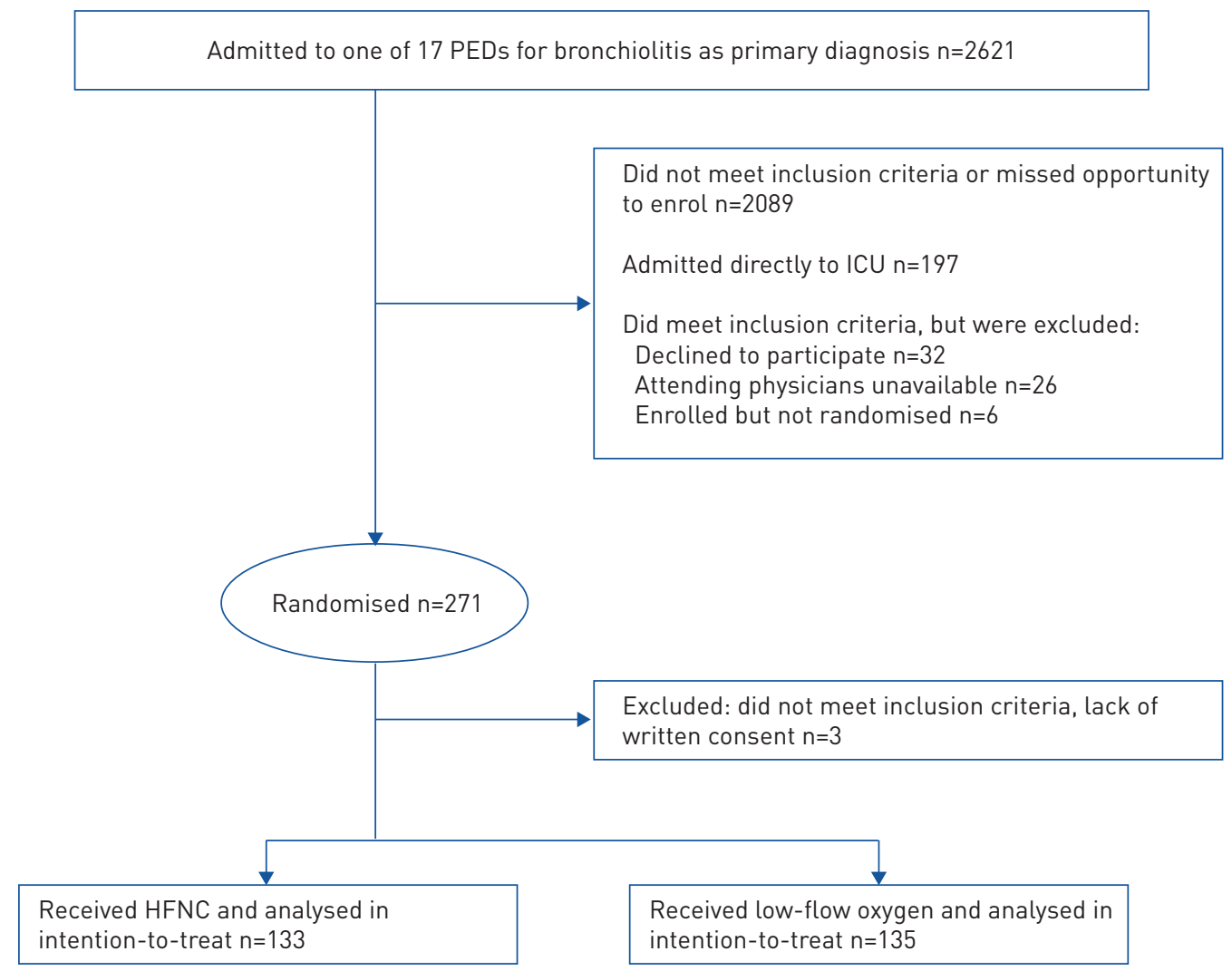

FIGURE 1 Eligibility, randomisation and follow-up of the study participants. PED: paediatric emergency department; ICU: intensive care unit; HFNC: high-flow nasal cannula. 


\begin{tabular}{|c|c|c|}
\hline & HFNC & Control \\
\hline Patients & 133 & 135 \\
\hline \multicolumn{3}{|l|}{ Characteristics } \\
\hline Age days & $68 \pm 48$ & $65 \pm 46$ \\
\hline Weight kg & $5.1 \pm 1.5$ & $4.9 \pm 1.4$ \\
\hline Female & 52 (39) & $65(48)$ \\
\hline Gestational age weeks & $38 \pm 2$ & $38 \pm 2$ \\
\hline Premature birth (<37 weeks) & $16(12)$ & $16(11)$ \\
\hline \multicolumn{3}{|l|}{ Clinical variable } \\
\hline Duration of symptoms before randomisation days & $3.3 \pm 2.1$ & $3.1 \pm 2.2$ \\
\hline Temperature ${ }^{\circ} \mathrm{C}$ & $37.2 \pm 0.6$ & $37.2 \pm 0.5$ \\
\hline Respiratory rate bpm & $53 \pm 13$ & $55 \pm 14$ \\
\hline Heart rate bpm & $156 \pm 18$ & $154 \pm 18$ \\
\hline $\mathrm{S}_{\mathrm{pO}_{2}} \%$ in room air & $90 \pm 3$ & $90 \pm 3$ \\
\hline $\mathrm{m}$-WCAS & $3.3 \pm 0.8$ & $3.1 \pm 0.7$ \\
\hline$P_{\mathrm{tCO}_{2}}^{\#} \mathrm{mmHg}$ & $50 \pm 11$ & $50 \pm 10$ \\
\hline $\mathrm{pH}$ & $7.34 \pm 0.07$ & $7.33 \pm 0.05$ \\
\hline \multicolumn{3}{|l|}{ Viral cause } \\
\hline Number tested & 103 & 105 \\
\hline RSV status & $85(82)$ & 87 (82) \\
\hline Other & $5(4)$ & $1(1)$ \\
\hline \multicolumn{3}{|c|}{$\begin{array}{l}\text { Data are presented as } n \text {, mean } \pm \mathrm{SD} \text { or } \mathrm{n}(\%) \text {. HFNC: high-flow nasal cannula; } S_{\mathrm{pO}_{2}} \text { : pulse } \\
\text { oximetry-measured oxygen saturation; m-WCAS: modified Wood clinical asthma score; } P_{\mathrm{tCo}_{2}} \text { : } \\
\text { transcutaneous carbon dioxide tension; RSV: respiratory syncytial virus. \#: available in } 49 \text { and } 43 \text { patients in } \\
\text { HFNC and control groups, respectively. }\end{array}$} \\
\hline
\end{tabular}

length of oxygen therapy (defined by the use of $>21 \% F_{\mathrm{iO}_{2}}$ in the HFNC group or nasal oxygen requirement in the control group) until discharge home or ICU-level admission was lower in the HFNC compared to control group $(\mathrm{p}=0.001)$. The short-term assessment of respiratory status is displayed in table 3 and did not show significant differences, except for the m-WCAS score at hour 1 and respiratory frequency at hours 6 and 12, in favour of the HFNC group.

\section{Safety}

All patients tolerated high-flow oxygen therapy well. None reported nasal mucosa or skin trauma. However, three pneumothoraces, including two cases of pneumomediastinum, occurred in patients randomised to the HFNC group; these both showed spontaneous favourable evolution without the need for chest drainage. The attending physicians suggested that the use of HFNC was probably or definitely related to these air leak events. No life-threatening serious adverse complications were reported, including no instances of endotracheal intubation or cardiac arrest.

\section{TABLE 2 Primary and secondary outcomes according to group}

\begin{tabular}{|c|c|c|c|c|}
\hline & HFNC & Control & OR $(95 \% \mathrm{CI})$ & Mean difference $(95 \% \mathrm{CI})$ \\
\hline Patients $\mathrm{n}$ & 133 & 135 & & \\
\hline $\begin{array}{l}\text { Primary outcome lescalating within } 7 \text { days) } \\
\text { Secondary outcome }\end{array}$ & $19(14)$ & $27(20)$ & $0.66(0.35-1.26)$ & \\
\hline Failure requiring ICU transfer within 7 days (ICU on-site or tertiary care) & $21(15)^{\S}$ & $26(19)^{f}$ & $0.78(0.41-1.41)$ & \\
\hline Length of nutritional support days ${ }^{\Uparrow}$ & $2.9 \pm 2.1$ & $2.4 \pm 2.2$ & & $0.50(-0.04-1.04)$ \\
\hline Length of oxygen support days ${ }^{+}$ & $1.7 \pm 1.7$ & $2.5 \pm 2$ & & $-0.80(-1.2--0.3)$ \\
\hline \multicolumn{5}{|c|}{$\begin{array}{l}\text { Data are presented as } n(\%) \text { or mean } \pm \text { SD of patients, unless otherwise stated. HFNC: high-flow nasal cannula; ICU: intensive care unit. } \\
\# \text { : noninvasive ventilation (NIV) or HFNC support in control group and NIV support in HFNC group in case of failure; }{ }^{\uparrow}: \text { until discharge at home } \\
\text { or ICU-level admission; }{ }^{+}: \text {inspiratory oxygen fraction }>21 \% \text { (HFNC group) or nasal oxygen requirement (control group) until discharge at home } \\
\text { or ICU-level admission; }{ }^{\S} \text { : two additional patients in study group who failed were kept on HFNC during their paediatric ICU stay; }{ }^{f}: \text { one patient } \\
\text { in control group who failed and escalated on HFNC was kept on the paediatric general ward. }\end{array}$} \\
\hline
\end{tabular}




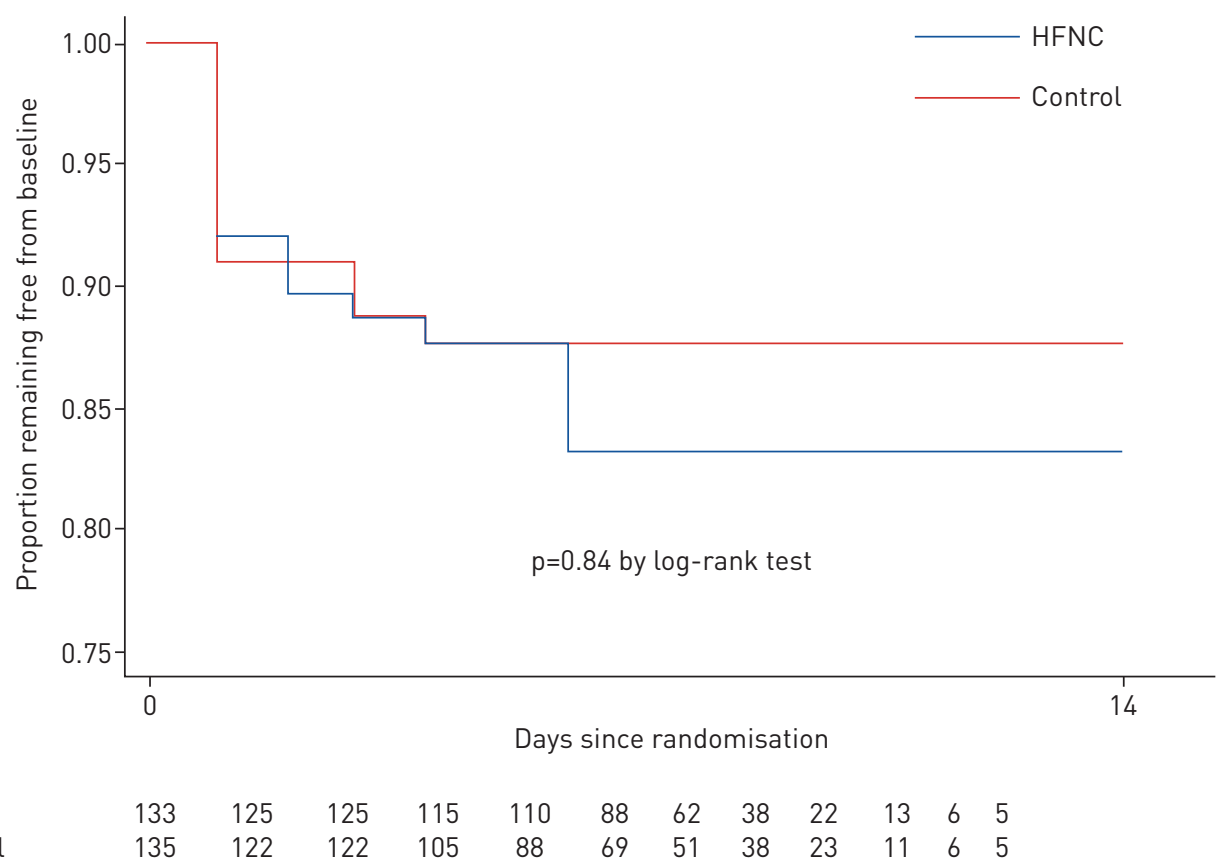

FIGURE 2 Kaplan-Meier plot of the proportion of moderate bronchiolitis patients remaining free of escalating treatment (defined by noninvasive ventilation or high-flow nasal cannula (HFNC) in control group and noninvasive ventilation in HFNC group onlyl since randomisation, according to group.

TABLE 3 Physiological variables and modified Wood clinical asthma score (m-WCAS) at $1 \mathrm{~h}$ and after 6 and $12 \mathrm{~h}$ after randomisation according to group

\begin{tabular}{|c|c|c|c|c|}
\hline & HFNC & Control & Mean difference $(95 \% \mathrm{CI})$ & p-value \\
\hline $\begin{array}{l}\text { Subjects } \mathrm{n} \\
1 \mathrm{~h}\end{array}$ & 133 & 135 & & \\
\hline$f_{\mathrm{R}}$ breaths $\cdot \min ^{-1}$ & $46 \pm 13$ & $50 \pm 13$ & $-4 .(-7.5--0.9)$ & 0.01 \\
\hline $\mathrm{HR}$ bpm & $151 \pm 18$ & $151 \pm 16$ & $0.3(-3.9-4.6)$ & NS \\
\hline $\mathrm{S}_{\mathrm{pO}_{2}} \%$ & $97 \pm 2$ & $97 \pm 3$ & $0.02(-0.6-0.7)$ & NS \\
\hline$F_{i 0^{2}}{ }^{2}$ or oxygen flow rate & $25 \pm 5 \%$ & $0.5 \pm 0.4 \mathrm{~L} \cdot \mathrm{min}^{-1}$ & & NA \\
\hline $\mathrm{m}$-WCAS change & $-0.098 \pm 0.22$ & $-0.036 \pm 0.23$ & $-0.06(-0.12--0.004)$ & $<0.01$ \\
\hline Apnoea events & 1 & 1 & & ND \\
\hline \multicolumn{5}{|l|}{$6 \mathrm{~h}$} \\
\hline$f_{\mathrm{R}}$ breaths $\cdot \min ^{-1}$ & $45 \pm 13$ & $49 \pm 15$ & $-3.6(-7.2-0.004)$ & 0.05 \\
\hline $\mathrm{HR}$ bpm & $152 \pm 17$ & $151 \pm 18$ & $1.2(-3.1-5.6)$ & NS \\
\hline $\mathrm{S}_{\mathrm{pO}_{2}} \%$ & $97 \pm 2$ & $97 \pm 2$ & $-0.04(-0.6-0.5)$ & NS \\
\hline$P_{\mathrm{tCO}} \mathrm{mmHg}$ & $44 \pm 7$ & $48 \pm 10$ & $-3.6(-8.5-1.2)$ & NS \\
\hline $\mathrm{F}_{\mathrm{iO}_{2}}^{\#}$ or oxygen flow rate & $26 \pm 6 \%$ & $0.5 \pm 0.3 \mathrm{~L} \cdot \mathrm{min}^{-1}$ & & NA \\
\hline $\mathrm{m}$-WCAS change & $-0.16 \pm 0.35$ & $0.11 \pm 0.31$ & $-0.05(-0.1-0.03)$ & NS \\
\hline Apnoea events & 0 & 0 & & ND \\
\hline \multicolumn{5}{|l|}{$12 \mathrm{~h}$} \\
\hline$f_{\mathrm{R}}$ breaths $\cdot \min ^{-1}$ & $42 \pm 13$ & $47 \pm 14$ & $-4.8(-8.3--1.2)$ & 0.01 \\
\hline $\mathrm{HR}$ bpm & $146 \pm 18$ & $145 \pm 18$ & $1.5(-3.1-6.1)$ & NS \\
\hline $\mathrm{S}_{\mathrm{pO}_{2}} \%$ & $97 \pm 2$ & $97 \pm 2$ & $-0.3(-0.9-0.2)$ & NS \\
\hline $\mathrm{F}_{\mathrm{iO}_{2}}{ }^{\#}$ or oxygen flow rate & $25 \pm 5 \%$ & $0.5 \pm 0.4 \mathrm{~L} \cdot \mathrm{min}^{-1}$ & & NA \\
\hline $\mathrm{m}$-WCAS change & $-0.23 \pm 0.31$ & $-0.15 \pm 0.38$ & $-0.07(-0.1-0.02)$ & NS \\
\hline
\end{tabular}

Data are presented as $\mathrm{n}$, mean $\pm \mathrm{SD}$ or $\mathrm{n}(\%)$, unless otherwise stated. HFNC: high-flow nasal cannula; $f_{\mathrm{R}}$ : respiratory frequency; $\mathrm{HR}$ : heart rate; $\mathrm{S}_{\mathrm{pO}_{2}}$ : pulse oximetry-measured oxygen saturation; $F_{\mathrm{iO}_{2}}$ : inspiratory oxygen fraction; $P_{\mathrm{tCO}_{2}}$ : transcutaneous carbon dioxide tension; $\mathrm{NS}$ : nonsignificant; NA: not applicable; ND: not determined. ${ }^{\# 2}$ : HFNC group; ${ }^{\natural}$ : control group. 


\section{Discussion}

In this multicentre randomised controlled trial involving infants with moderate bronchiolitis admitted to PEDs or inpatient wards, there was no evidence of a lower rate of failure leading to noninvasive ventilation support in patients receiving high-flow oxygen therapy compared to the control group. There was no significant between-group difference in the rate of ICU admission, while a marginal benefit of HFNC was observed for short-term respiratory parameters or length of oxygen therapy. However, in the HFNC group, three device-associated air leak syndromes were reported.

Our findings are partially supported by the results of two recent randomised trials, which found no difference in ICU admission rates between the two strategies $[14,15]$.

Regarding the observation that the time to wean off oxygen favoured the HFNC group, this difference may be considered irrelevant, consistent with the negative results reported in the two previously published RCTs (i.e. no significant difference in length of oxygen support between the HFNC and control group).

The first single-centre RCT was designed to demonstrate a reduction in the time to wean off oxygen. No difference was found between the two groups for the primary outcome or in the proportion of patients transferred to the PICU. However, although the percentage of children who experienced treatment failure was lower in the HFNC group ( $14 \%$ compared to $33 \%$ in the standard therapy group; $p=0.0016$ ), the study was underpowered for this secondary end-point. Finally, the relatively low flow setting of $1 \mathrm{~L} \cdot \mathrm{kg}^{-1} \cdot \mathrm{min}^{-1}$ in the HFNC group, the low mean m-WCAS score (compared to our data) and the rate of crossover in the standard group raised concerns about generalising these findings to other wards [14]. The crossover rate makes it difficult to draw definitive conclusions regarding the usefulness of high-flow oxygen therapy in very low-severity forms of bronchiolitis. The second study, a large multicentre RCT, aimed to compare HFNC (flow setting of $2 \mathrm{~L} \cdot \mathrm{kg}^{-1} \cdot \mathrm{min}^{-1}$ ) to standard therapy with the primary outcome as the rate of escalating therapy, which was defined as a heterogeneous composite failure criterion including meeting an early warning sign-driven protocol, admission to the ICU and/or crossover to HFNC in the control patients. Despite a significantly higher rate of failure-free days in favour of the HFNC group, neither the proportion of patients admitted to the ICU nor the number of oxygen-free days were found to be significantly different. Moreover, the number of patients who underwent noninvasive ventilation in the failure group was unknown [15]. However, the clinical benefit highlighted in these two RCTs (i.e. the proportion of failure-free days in favour of HFNC) is consistent with our observed short-term improvements in respiratory rate, $\mathrm{m}$-WCAS score or mean $P_{\mathrm{tCO}_{2}}$ at failure in the HFNC group. These findings are consistent with an extensive literature focused on the physiological benefits of HFNC in infants and adults, which stress the benefit of reduced work of breathing.

Finally, several concerns have been noted regarding cost-effectiveness in terms of the high rate of crossover in the control group, as this indicates bias of the attending physicians toward HFNC as a beneficial therapy at the time of crossover, even though the evidence for the benefit of HFNC in "moderate" bronchiolitis (i.e. all patients admitted to the ward and requiring oxygen to target a $S_{\mathrm{pO}_{2}}$ level of 92-98\%) remains to be established [20].

It is worth noting that our $\sim 10 \%$ inclusion rate of total infants admitted to the PED with bronchiolitis as a primary diagnosis is quite similar to that in the study by FrankLIN et al. [15]. Interestingly, our failure rates in the HFNC and control groups (20\% and 14\%, respectively) are comparable to their subgroup of patients in recruiting institutions with an on-site PICU. However, neither the inclusion and/or failure criteria nor the primary end-point were similar between the two studies, which makes these comparisons much more difficult, especially because our pragmatic "real-world" trial was not designed to explain these differences.

Indeed, our study included infants aged $<6$ months during two consecutive winter epidemic outbreaks in order to decrease the risk of including infant asthma patients and to target subgroups at higher risk for admission to the ICU, in contrast to previous RCTs [1, 2, 21, 22]. Furthermore, we chose an escalating respiratory support requirement (mainly with nCPAP) as a pragmatic judgment criterion because it is currently considered standard first-line treatment for severe cases admitted to the PICU in most developed countries, despite a lack of evidence from RCTs $[4,7,12]$. Indeed, we and others suggest that avoiding admission to the PICU or noninvasive support are more relevant end-points, as both are associated with the PICU seasonal burden, substantial complications and higher costs [23]. Finally, some features are likely to reduce interpretation bias, including the fact that the design did not allow crossover between the groups and the absence of a PICU in all but one recruiting centre.

Although the study did not use a crossover design, 10 infants from the control group were escalated to HFNC (nine in the ICU; one remained in the ward) (table 2). Once the patient met the failure criteria in each group, indicating release from the study, physicians were not able to both escalate and remain in the randomisation arm, meaning that the patient had to be admitted to intermediate level care or the ICU. It should be noted that the PICU team caring for infants in the failure group was not involved in the study design. Thus, the 
choice to escalate support was entirely at the entire discretion of the paediatric intensivist, which is why several patients who failed in the control arm received support with HFNC after their ICU admission.

We chose a $3 \mathrm{~L} \cdot \mathrm{kg}^{-1} \cdot \mathrm{min}^{-1}$ flow rate in our study given that a previous physiological study suggested that maintaining a pharyngeal pressure-to-flow relationship above $2 \mathrm{~L} \cdot \mathrm{kg}^{-1} \cdot \mathrm{min}^{-1}$ helps reduce work of breathing [24]. Moreover, a similar flow rate close to or above $3 \mathrm{~L} \cdot \mathrm{kg}^{-1} \cdot \mathrm{min}^{-1}$ has also been used in two other RCTs that included premature newborns after extubation $[25,26]$. We could not rule out worsened work of breathing in some patients due to individual excess inflow rate and/or discomfort, which would mask a potential benefit in the HFNC group. This is consistent with a recent RCT, which indeed suggested that a $3 \mathrm{~L} \cdot \mathrm{kg}^{-1} \cdot \mathrm{min}^{-1}$ flow rate did not reduce the risk of treatment failure compared to the $2 \mathrm{~L} \cdot \mathrm{kg}^{-1} \cdot \mathrm{min}^{-1}$ arm in severe bronchiolitis [16]. However, the short-term improvement in respiratory rate or m-WCAS score in the HFNC group is consistent with previous literature evaluating the physiological benefits of HFNC in infants and adults [24, 27-29].

Serious, unexpected adverse events encountered in the HFNC group are a matter of concern, especially because potentially serious air-leak syndromes have previously been reported with high-flow oxygen therapy devices $[19,30]$. We propose several hypotheses, including nasal prong sizes that are unable to provide sufficient nostril leakage in some patients (unfortunately, a fixed size apparatus was used for the entire study group), incorrect pacifier use and/or an excessive fixed-flow rate setting at $3 \mathrm{~L} \cdot \mathrm{kg}^{-1} \cdot \mathrm{min}^{-1}$ in our study.

The limitations and weaknesses of our study include the fact that the median m-WCAS score was slightly but significantly higher at randomisation in the HFNC group, indicating that some inclusion bias cannot be ruled out, though it should be emphasised that this significant difference was not clinically relevant. Given the substantial difference in a physician deciding to escalate to HFNC (especially if the patient is to remain in the ward) versus escalating to NIV, we cannot rule out an evaluation bias regarding the inescapable nonblinded design features, as severity at the time of failure could be lower in the control group despite a lack of evidence (supplementary table E2). In the same way, not knowing the exact time from admission to randomisation make the comparison more challenging. Another potential interpretation bias could be the $\mathrm{S}_{\mathrm{pO}_{2}}$ target chosen for oxygen therapy and failure criteria, given that our chosen value is substantially higher than the $90 \%$ threshold listed in AAP guidelines threshold and subsequently recommended by the WHO. The translatability of these results remains, and our findings are likely not generalisable to most centres [31]. However, it could be argued that the number patients who failed in both groups due to hypoxaemia was well balanced (supplementary table E2) and similar to FrANKLIN et al.'s [15] study results using a similar oxygen therapy threshold. The failure rate observed in the control group was lower than expected (20\%), and thus the number of patients included in the study did not allow for detection of a minimum difference of $60 \%$ with a similar power. This combination of factors puts the study at risk of being underpowered. Attending physicians were not always available $24 \mathrm{~h} / 7$ days a week, which may have limited the representativeness of our population by reducing the number of enrolment opportunities.

In conclusion, the results of our study do not support the pre-emptive and routine use of respiratory support by HFNC at a setting of $3 \mathrm{~L} \cdot \mathrm{kg}^{-1} \cdot \mathrm{min}^{-1}$ in patients admitted to a PED and then onward for moderate viral bronchiolitis. Although HFNC may not be best used as a general practice, the criteria for its use in paediatric wards should be further defined.

Acknowledgements: We thank the participating families, the staff of the emergency and paediatric departments, the research assistants at the trial sites, Clinical Research Unit, Bicêtre Hospital, Paris-Saclay University (Domitille Molinari, Marylise Adechian, Héllène Agostini), Christophe Milési (Montpellier University Hospital, Montpellier, France) for proofreading and fruitful comments and Clémentine Roy (Paris, France) for help in editing.

The following are members of the Bronchopti study group, listed in alphabetical order: Sakina Benkaddouss, Meaux Hospital; Priscilla Binet, Bicêtre University Hospital; Claire Bretagne, Béclère University Hospital; Anne Chace, Villeneuve Saint George Hospital; Edwidge Dakouri, Villeneuve Saint George Hospital; Yvan De La Monneraye, Ambroise Paré University Hospital; Céline Delestrain, Intercommunal Creteil Hospital; Leila Destruys, Bicêtre University Hospital; Danielle Dubrez, Villeneuve Saint George Hospital; Marc Duval-Arnould, Bicêtre University Hospital; Rachel El Samad, Meaux Hospital; Boris Gbacko, Melun Hospital; Emilie Georget, Villeneuve Saint George Hospital; Charlotte Girod, Orsay Hospital; François Gouraud, Meaux Hospital; Claire Grinwood, Ambroise Paré University Hospital; Thomas Hellwig, Fontainebleau Hospital; Maud Kernemp, Poissy Hospital; Marie Khelfa, Chartres Hospital; Aurélie Lemaire, Poissy Hospital; Iulia Marian, Orsay Hospital; Laurence Mathivon, Meaux Hospital; Elodie Merlot and Marie Monfort, Meaux Hospital; Gabrielle Naudet, Villeneuve Saint George Hospital; Laure Picard, Chartres Hospital; Delphine Regnard, Bicêtre University Hospital; Noureddine Riahi, Chartres Hospital; Charlotte Rougeoreille, Melun Hospital; Nathalie Sannier, Montargis Hospital; Clémentine Specht, Béclère University Hospital; Andrea Valean, Ambroise Paré University Hospital; Cécile Yakovleff, Poissy Hospital; Edwige D.A. Zoclanclounon, Chartres Hospital.

Conflict of interest: None declared.

Support statement: The study was funded by a grant from Programme Hospitalier de Recherche Clinique - PHRC 2016 (Ministère de la santé AORC 14056, P150931/IDRCB 2016-A00568-43). High-flow oxygen therapy devices and 
consumable materials were supplied by Fisher \& Paykel Healthcare, Auckland, New Zealand. Funding information for this article has been deposited with the Crossref Funder Registry.

\section{References}

1 Ricart S, Marcos MA, Sarda M, et al. Clinical risk factors are more relevant than respiratory viruses in predicting bronchiolitis severity. Pediatr Pulmonol 2013; 48: 456-463.

2 Essouri S, Laurent M, Chevret L, et al. Improved clinical and economic outcomes in severe bronchiolitis with pre-emptive nCPAP ventilatory strategy. Intensive Care Med 2014; 40: 84-91.

3 Che D, Nicolau J, Bergounioux J, et al. Bronchiolite aiguë du nourrisson en France: bilan des cas hospitalisés en 2009 et facteurs de létalité. [Bronchiolitis among infants under 1 year of age in France: epidemiology and factors associated with mortality]. Arch Pédiatr 2012; 19: 700-706.

4 National Institute for Health and Care Excellence (NICE). Bronchiolitis in Children: Diagnosis and Management. NICE Guideline, 2015. www.nice.org.uk/Guidance/NG9 Date last updated: June 1, 2015.

5 Ralston SL, Lieberthal AS, Meissner HC, et al. Clinical practice guideline: the diagnosis, management, and prevention of bronchiolitis. Pediatrics 2014; 134: e1474-e1502.

$6 \quad$ Florin TA, Plint AC, Zorc JJ. Viral bronchiolitis. Lancet 2017; 389: 211-224.

7 Milési C, Essouri S, Pouyau R, et al. High flow nasal cannula (HFNC) versus nasal continuous positive airway pressure (nCPAP) for the initial respiratory management of acute viral bronchiolitis in young infants: a multicenter randomized controlled trial (TRAMONTANE study). Intensive Care Med 2017; 43: 209-216.

8 Schlapbach LJ, Schaefer J, Brady A-M, et al. High-flow nasal cannula (HFNC) support in interhospital transport of critically ill children. Intensive Care Med 2014; 40: 592-599.

9 Schibler A, Pham TMT, Dunster KR, et al. Reduced intubation rates for infants after introduction of high-flow nasal prong oxygen delivery. Intensive Care Med 2011; 37: 847-852.

10 Mayfield S, Bogossian F, O'Malley L, et al. High-flow nasal cannula oxygen therapy for infants with bronchiolitis: pilot study. J Paediatr Child Health 2014; 50: 373-378.

11 Kallappa C, Hufton M, Millen G, et al. Use of high flow nasal cannula oxygen (HFNCO) in infants with bronchiolitis on a paediatric ward: a 3-year experience. Arch Dis Child 2014; 99: 790-791.

12 Sinha IP, McBride AKS, Smith R, et al. CPAP and high-flow nasal cannula oxygen in bronchiolitis. Chest 2015; 148: 810-823.

13 Javouhey E, Barats A, Richard N, et al. Non-invasive ventilation as primary ventilatory support for infants with severe bronchiolitis. Intensive Care Med 2008; 34: 1608-1614.

14 Kepreotes E, Whitehead B, Attia J, et al. High-flow warm humidified oxygen versus standard low-flow nasal cannula oxygen for moderate bronchiolitis (HFWHO RCT): an open, phase 4, randomised controlled trial. Lancet 2017; 389: 930-939.

15 Franklin D, Babl FE, Schlapbach LJ, et al. A randomized trial of high-flow oxygen therapy in infants with bronchiolitis. N Engl J Med 2018; 378: 1121-1131.

16 Milési C, Pierre A-F, Deho A, et al. A multicenter randomized controlled trial of a 3-L/kg/min versus 2-L/kg/min high-flow nasal cannula flow rate in young infants with severe viral bronchiolitis (TRAMONTANE 2). Intensive Care Med 2018; 44: 1870-1878.

17 McKiernan C, Chua LC, Visintainer PF, et al. High flow nasal cannulae therapy in infants with bronchiolitis. $J$ Pediatr 2010; 156: 634-638.

18 Kelly G, Simon H, Sturm J. High-flow nasal cannula use in children with respiratory distress in the emergency department: predicting the need for subsequent intubation. Pediatr Emerg Care 2013; 29: 888-892.

19 Wing R, James C, Maranda LS, et al. Use of high-flow nasal cannula support in the emergency department reduces the need for intubation in pediatric acute respiratory insufficiency. Pediatr Emerg Care 2012; 28: 1117-1123.

20 Meskill SD, Moore RH. High-flow oxygen therapy in infants with bronchiolitis. N Engl J Med 2018; 378: 2444.

21 Thia LP, McKenzie SA, Blyth TP, et al. Randomised controlled trial of nasal continuous positive airways pressure (CPAP) in bronchiolitis. Arch Dis Child 2008; 93: 45-47.

22 Mansbach JM, Piedra PA, Stevenson MD, et al. Prospective multicenter study of children with bronchiolitis requiring mechanical ventilation. Pediatrics 2012; 130: e492-e500.

23 Freire G, Kuppermann N, Zemek R, et al. Predicting escalated care in infants with bronchiolitis. Pediatrics 2018; 142: 13.

24 Milési C, Baleine J, Matecki S, et al. Is treatment with a high flow nasal cannula effective in acute viral bronchiolitis? A physiologic study. Intensive Care Med 2013; 39: 1088-1094.

25 Yoder BA, Stoddard RA, Li M, et al. Heated, humidified high-flow nasal cannula versus nasal CPAP for respiratory support in neonates. Pediatrics 2013; 131: e1482-e1490.

26 Manley BJ, Owen LS, Doyle LW, et al. High-flow nasal cannulae in very preterm infants after extubation. $N$ Engl J Med 2013; 369: 1425-1433.

27 Hough JL, Pham TMT, Schibler A. Physiologic effect of high-flow nasal cannula in infants with bronchiolitis. Pediatr Crit Care Med 2014; 15: e214-e219.

28 Rubin S, Ghuman A, Deakers T, et al. Effort of breathing in children receiving high-flow nasal cannula. Pediatr Crit Care Med 2014; 15: 1-6.

29 Mauri T, Turrini C, Eronia N, et al. Physiologic effects of high-flow nasal cannula in acute hypoxemic respiratory failure. Am J Respir Crit Care Med 2017; 195: 1207-1215.

30 Hegde S, Prodhan P. Serious air leak syndrome complicating high-flow nasal cannula therapy: a report of 3 cases. Pediatrics 2013; 131: e939-e944.

31 Cunningham S, Rodriguez A, Adams $\mathrm{T}$, et al. Oxygen saturation targets in infants with bronchiolitis (BIDS): a double-blind, randomised, equivalence trial. Lancet 2015; 386: 1041-1048. 